\title{
Fragmentos de memoria, erotismo y escritura en Juntando mis pasos de Elías Nandino
}

\author{
Gerardo Bustamante Bermúdez \\ Universidad Autónoma de la Ciudad de México
}

No me importa cómo juzguen mi vida; yo traté de vivirla haciendo estrictamente lo que ella apetecía [...]

Elías NANDINO

RESUMEN: Juntando mis pasos (2000) de Elías Nandino es la autodefensa del poeta a
la biografía escrita en 1986 por Enrique Aguilar. En este artículo se analiza la cons-
trucción biográfica del poeta octogenario que, casi ciego y sordo, hace un ejercicio
de la memoria para recuperar fragmentos de su vida. A partir de este análisis el autor
destaca temas como la homosexualidad, la vida cultural en el México de los veintes
a los ochentas, la familia y el rechazo a la heteronormatividad. Mediante este trabajo
se integra Juntando mis pasos, obra que ha sido poco estudiada, al conjunto de testi-
monios autobiográficos de la cultura mexicana del sigo XX.

ABSTRACT: Juntando mis pasos (2000) by Elías Nandino is the self-defense of a poet against the biography written in 1986 by Enrique Aguilar. This article analyzes the biographic construction of the eighty-year old poet, who practically blind and deaf, performs an exercise of memory to recover fragments of his life. From this analysis the author develops themes like homosexuality, the cultural life in Mexico from the 1920 's to the 80 's, the family and rejection of hetero-normativity. This work joins together Juntando mis pasos, a piece that has been little-studied, with the group of autobiographic testimonies about Mexican culture in the 20th century.

Palabras ClaVE: autobiografía, heterodoxia sexual, erotismo, autodefensa, homosexualidad, transgresión.

KeY WORDS: autobiography, sexual heterodoxy, eroticism, self-defense, homosexuality, transgression.

Elías Nandino Vallarta (1900-1993) es uno de los poetas mexicanos menos estudiados por la crítica literaria; incluso, siendo amigo y contemporáneo del grupo "Contemporáneos", no figura propiamente como miembro. Para algunos, la obra poética del autor coculense tiene un valor literario menor que la de Xavier Villaurrutia, Salvador Novo 
o Carlos Pellicer, por mencionar sólo tres poetas con los que se le ha comparado literariamente.

A partir de la publicación de la biografía no autorizada Elías Nandino: una vida no/velada (1988) del periodista Enrique Aguilar, el nombre de Elías Nandino se conoce más por su vida muchas veces "escandalosa” que por su vena de poeta o director de la revista Estaciones, publicación que abriría espacios para las nuevas voces de la poesía y la narrativa mexicana principalmente.

A manera de autodefensa, Elías Nandino decidió escribir una versión que desmentiría lo escrito por Aguilar, y es así como surge Juntando mis pasos, publicado de manera póstuma en el 2000. A decir del propio autor, este libro es una reescritura de la autobiografía que comenzó a escribir a los treinta años, y cuyo manuscrito perdió. El texto de Nandino se emparenta con La estatua de sal (1998) de Salvador Novo en el sentido de que son escritos autobiográficos de dos escritores mexicanos homosexuales del siglo xx que hablan de sus deseos, experiencias, realizaciones homoeróticas y que trazan una línea del ambiente cultural e histórico del siglo Xx mexicano, desde la Revolución vivida durante la infancia, hasta los años ochentas — en el caso de Nandino-, pues el texto de Novo sólo incluye sus primeros veinte años. Juntando mis pasos nos permite leer un México convulso y con acelerados cambios sociales, políticos, económicos y culturales durante el siglo XX.

El libro de Nandino provocó en lectores y críticos reacciones diversas. Para Víctor Roura — cuyo texto merece un estudio más serio que el que aquí puedo hacer - la autobiografía de Nandino:

sólo conduce a su impulsiva conducta homosexual. No hay razonamiento sobre el quehacer poético, ni un pensamiento político ni tampoco un concepto sobre el arte. Pareciera que, desde la niñez, lo único que movía a este hombre era la compulsión sexual. Ni un acercamiento con el grupo de Los Contemporáneos modificó, o conformó, su visión literaria [...] su obsesión por el sexo masculino era tal que no se daba tiempo para ventilar y airear, discutir y polemizar, sus ideas sobre el arte y la escritura, si es que poseía, acaso, alguna (Roura: 70).

Considero a Juntando mis pasos un texto importante que abarca la visión de un escritor testigo y partícipe de casi todo el siglo Xx. Desde mi punto de vista, a Nandino le interesaba hablar de su vida en general, y de sus experiencias homoeróticas de manera particular. Encontrar o 
no razonamientos sobre el quehacer poético del autor, sobre el concepto del arte o su posición política, no es decisivo ni importante, sobre todo cuando el mismo autor se ve obligado a escribir una réplica a su biografía no autorizada que hace énfasis en su vida privada. ${ }^{1}$ Sus opiniones sobre literatura las encontramos en varios artículos críticos que publicó en Estaciones, así como en muchos de sus poemas.

Dice Juan Antonio Rosado en Erotismo y misticismo - a propósito de la obra de Juan García Ponce- que la "escritura del deseo a través de la palabra permite apropiarse de una apariencia y convertirla en obra; puede atrapar un objeto al nombrarlo o encontrar lo probable al invocarlo, pero en ambos casos su función es doble: 'realidad de lo real y realidad de lo irreal'. La representación nos comunica con el mundo, y si disfraza la realidad es sólo para que volvamos a ella" (49). Así, la representación de "la realidad" del poeta — con todo lo subjetivo y ficticio que tenga - permite al lector recoger fragmentos de la vida solitaria, sufrida, transgresora, erótica y gozosa del autor $\mathrm{y}$, aunque se trate de una representación subjetiva e ilusoria, hay que tener en cuenta que "La relación entre arte y realidad no es nunca directa, sino que está mediatizada por mecanismos ilusorios, por más referentes sociales o históricos que contenga” (50).

Juntando mis pasos — como lo sugiere el título de alguna formaes un ejercicio de la memoria recuperada desde la etapa infantil, hasta la época en que el autor experimenta una soledad por su "impotencia sexual" y su forzado renunciamiento a los amores y encuentros sexuales con jóvenes. Temas importantes a lo largo del texto son la familia, principalmente las figuras femeninas a las que ve como débiles; el amor que se sufre, goza, modifica y termina; las experiencias homoeróticas, la amistad, la escritura poética que sustituye al acto sexual cuando éste ya no es posible, la soledad, y el poeta mismo en su rol de activo, protector y padre.

Juntando mis pasos es un texto dividido en cuarenta y un capítulos - posiblemente una referencia al polémico baile de los 41 en la ciudad

\footnotetext{
${ }^{1}$ La autobiografía de Nandino tiene por objetivo ayudar a la liberación de los individuos que "padecen" una homosexualidad silenciada, así lo hace saber en la biografía de Enrique Aguilar: "Quiero que estas confesiones ayuden a que dentro de la sociedad la gente tenga libertades; que pueda vivir y ser como piense que es mejor, sin tener que simular para evitar el juicio de los demás” (19).
} 
de México a principios de siglo_- ${ }^{2}$ una nota aclaratoria y un prefacio. Generalmente los capítulos son breves y estructurados de una manera más o menos cronológica, a excepción de las digresiones que el poeta hace en el último capítulo donde vuelve hacer comentarios de su vida juvenil. Podría decirse que la mirada retrospectiva del poeta se acompaña también de un deseo por comprender o, en todo caso, rescatar fragmentos de su memoria, desde la niñez, hasta la etapa madura y compartirlos con su lector, pero nunca con el objetivo de justificar su vida transgresora según la mirada social y religiosa.

A diferencia de La estatua de sal de Novo que llega a tener un tono exhibicionista y desafiante, en el texto de Nandino se leen momentos melancólicos, sobre todo si tomamos en cuenta las condiciones precarias de salud y la soledad que sentía el escritor octogenario al momento de escribir su autobiografía. Su impotencia sexual, los problemas visuales y auditivos, lo apartan de una vida gozosa. La "Nota" que abre el texto, sirve, por un lado, para reconocer públicamente la labor del joven poeta Enrique López Navarro, quien a manera de un hijo desinteresado, le ayuda a mecanografiar lo que sería su verdad y para desmentir el texto de Enrique Aguilar; por otro lado, Nandino se dedica a hacer un recuento de cómo se dio su contacto con Aguilar, a quien acusa de indecente, indiscreto e irrespetuoso y de ser un macho que "piensa con los testículos" (Nandino 2000: XI). ${ }^{3}$

La autobiografía de Elías Nandino además de ser un texto que nos permite leer al México del siglo Xx, puede ser también objeto de análisis psicoanalistas. Desde el "Prefacio" llama la atención que todavía a la edad de ochenta y siete años, el poeta hable de la homosexualidad como

\footnotetext{
${ }^{2}$ Baile celebrado en noviembre de 1901 en la ciudad de México, donde simulando una cena club aristócrata, homosexuales de la sociedad porfirista, la mayoría de ellos casados, fueron sorprendidos por los gendarmes, enjuiciados y encarcelados por llevar a cabo prácticas amorosas y sexuales desde la clandestinidad y lo "anormal". Es bien sabido que eran cuarenta y dos homosexuales, pero como uno de ellos era el yerno de don Porfirio Díaz, eliminaron su nombre de la lista. Sobre una literaturización de este tema, véase la novela de Jaques Paire titulada De caracoles y escamoles. Un cocinero francés en tiempos de don Porfirio, editada por Alfaguara en 1995. Sobre la vida, costumbres, ocupaciones, homofobias y lugares homosexuales en la ciudad de México en el siglo Xx, Carlos Monsiváis ha escrito páginas interesantes, por ejemplo, los artículos que publicó en la revista Debate feminista (véase bibliografía al final de este artículo).

${ }^{3}$ A partir de aquí, cuando cite parte de este texto, sólo colocaré el número de página, entre paréntesis, después de la cita.
} 
una condición anormal. Si bien es cierto que a lo largo de Juntando mis pasos vemos a un Nandino sincero, que vivió su sexualidad como quiso, él mismo al utilizar términos como "heterodoxia sexual" se asume como un hombre "entre" lo deseado y lo prohibido, entre el pecado y la transgresión. Por su profesión y experiencia como médico, categoriza y distingue al "hombre homosexual del hombre auténtico" (XVIII), considera la homosexualidad como una "enfermedad" incurable. Así, según sus propias categorías, Nandino es un hombre anormal, enfermo e inauténtico. Evidentemente, el poeta está pensando en la "anormalidad del homosexual" comparada con el prototipo del macho mexicano: borracho y mujeriego, como su padre. Sobre este punto, es importante señalar que la genealogía familiar está compuesta por mujeres abnegadas y débiles, dedicadas a los hijos y al hogar, así como de hombres que trabajan arduamente, que se emborrachan cuando desean y tienen más de una familia.

Sobre la homosexualidad silenciada en una época donde se reprimen las prácticas homoeróticas y se exige socialmente una normatividad sexual, Nandino apunta dos casos particularmente:

Mi tío Guillermo murió de hemorroides. Recuerdo que ya no me llevaban con él porque decían que tenía cáncer y que era contagioso. Después cuando ya estudié medicina, colegí que mi tío murió de cáncer en el recto, que quizás era homosexual, porque siempre fue solitario y poco se comunicaba con la demás familia (2).

Como médico, Nandino anota las constantes simulaciones de homosexuales hombres y mujeres que han cumplido con su rol de género y reproducción biológica y, que frente a la frustración, han solicitado su ayuda:

Hombres casados que hacían hijos por cumplir con su mujer, sin ningún afecto, sin la pasión necesaria para hacer los coitos como actos auténticos, y producían hijos carentes de sensibilidad porque los hijos no solamente se hacen de la unión carnal sino también con la unión espiritual. Lo mismo mujeres casadas, que casi enloquecidas iban a pedir auxilio por el pavor y el odio que les daba tener que acostarse con sus maridos (XVII). ${ }^{4}$

\footnotetext{
${ }^{4}$ Al final de Juntando mis pasos, Nandino vuelve sobre la preceptiva del psicoanálisis al mencionar que los hijos que se procrean sin la mediación del amor, nacen sin carácter. Estas ideas, aprendidas de su maestro, el psicoanalista Santiago Ramírez, y leídas en sus cursos como estudiante de medicina lo llevan a rechazar y horrorizarse ante la idea de te-
} 
Durante la vejez, Elías Nandino dice sentirse contento con su condición de homosexual y compara el gozo y la libertad de la entrega que experimentó con otros hombres. Asegura que: "los hombres más felices no han tenido las noches de amor que yo tuve, porque ellos las han gozado normalmente y yo las gocé con lo prohibido. Mi homosexualidad es auténtica; yo nací con ella en los huesos y en mi sangre, y no me avergüenzo" (57). Esta declaración de la exaltación de su gozo, además de repetirse constantemente en el texto, aparece en varios poemas de Erotismo al rojo blanco (1983) y en el "Poema prefacio" que cierra Juntando mis pasos (199):

$$
\begin{aligned}
& \text { Por ella fui lascivo } \\
& \text { y no me ha dejado puro } \\
& \text { ni un poro de mi cuerpo. } \\
& \text { Fue tal mi apego } \\
& \text { a los desmanes } \\
& \text { de su carnal orgía, } \\
& \text { que a mis ochenta y dos años } \\
& \text { de su infierno en ruinas } \\
& \text { aún estoy creando mi poesía. }
\end{aligned}
$$

Para hablar de la niñez, ocupa diez capítulos. A través de la reproducción de la mirada infantil en el discurso, el autor narra sus experiencias con niños de su edad, el descubrimiento de las relaciones sexuales entre los padres, sus impresiones con una niña masculina, las prácticas zoofílicas y los abusos sexuales que los sacerdotes hacían a su persona.

El Nandino niño, con un desconocimiento de las prácticas sexuales de los padres, dice: "desperté al oír ruido y movimiento de cama. Mi madre se quejaba, pero no como cuando mi padre le pegaba y yo salía corriendo a pedir auxilio a mis vecinos. Era un quejido diferente que me avergonzaba y me lastimaba y sentía coraje contra mi padre. Des-

ner un hijo con una joven de buena posición con la que se involucra cuando comenzaba la carrera: "me dijo que se le había detenido la regla, y yo sufrí intensamente, igual que con una novia que había tenido antes, de modo que me convencí de que tenía una fobia a reproducirme en un hijo. Había leído mucho, especialmente en psicoanálisis, en que en los matrimonios en los que se practicaban los actos sexuales por costumbre y no por amor, nacían los hijos sin temperamento ni sensibilidad hacia la vida” (191). 
de esa vez me sentí más distante de él" (24-25). ${ }^{5}$ La presentación que hace el poeta de su padre es la de un macho violento y dominador. ${ }^{6} \mathrm{La}$ figura paterna en Nandino no es un modelo que le interese reproducir. La madre, por el contrario, es digna de conmiseración; la ve como la víctima de un verdugo al que Nandino le tiene celos y desconfianza, y que simbólicamente según Freud, sería su rival. Con la madre se establece una relación edípica no resuelta del todo; la ve como modelo de perfección, incluso desde la edad adulta: "Debo decir que yo amaba a mi madre místicamente, como si fuera una santa, exenta de todo pecado" (26). La desprotección y violencia del padre, así como la sumisión y "santidad" de la madre, quizás puedan hablar de una homosexualidad desarrollada en Nandino quien, al rechazar el modelo heteronormativo del dominador y la dominada, opta de manera inconsciente por conservar su rol activo en las relaciones, y ser una especie de padre protector con sus amantes a partir de la juventud, es decir, que posee elementos femeninos y masculinos en cuanto a la construcción genérica.

En la infancia, Nandino refiere haber tenido relaciones amorosas con niñas de su edad por una especie de curiosidad, sin embargo, no hay deseo; es un amor infantil platónico que se asemeja más a un cariño inocente que no despierta sensaciones ni deseos sexuales. Por el contrario:

Por las noches soñaba, pero no con mis novias, sino con mis amigos. Poco a poco se fue definiendo la causa de mi profunda inquietud y me di cuenta de que lo que me gustaba estaba prohibido por mi religión y por la sociedad. Sentía tristeza. Escuchaba cómo hablaban mis amigos de sus novias [...] reflexionaba que yo era distinto. Fue mi tiempo de transición, en que poco a poco, me fui aceptando como era y, a la vez, considerando que era mi razón de vivir (32).

Al hablar de definición y aceptación de un género distinto al establecido por su religión y sociedad, Nandino pretende afirmar su condición

\footnotetext{
${ }^{5}$ En Elías Nandino: una vida no/velada, se escribe: "intuí que no la estaba maltratando de la misma manera violenta que hacía necesario que yo saliera a gritarle a los vecinos, pero que de todos modos sí le estaba haciendo daño de una forma que, sin saber bien la razón, me pareció todavía más imperdonable" (31).

${ }^{6}$ En el texto de Enrique Aguilar, se presenta con mayor detalle a la figura paterna: las constantes infidelidades conyugales, su machismo exacerbado, la avaricia, su estancia en la cárcel de Cocula, y el miedo que provocaba en los hijos su sola presencia en la casa (27-32).
} 
de homosexual, sin embargo, a pesar de la aceptación / liberación, a lo largo del texto, el autor no descarta sus ideas de la "marca" y la "diferencia" como algo anormal en él.

Los encuentros homoeróticos con otros niños en los solares y en el jagüey de su rural Cocula, Jalisco, hablan de un deseo por conocer sexualmente al otro, aunque con el placer convive el miedo y la culpa. Encuentro decisivo para su aceptación como homosexual es la efímera, pero pasional relación con Lencho, un joven que es asesinado tiempo después por otro joven en una rivalidad amorosa heterosexual. Al hablar de la experiencia homoerótica con Lencho, Nandino confiesa el descubrimiento infantil del sexo del otro y del placer que provoca: "Siguió haciendo movimientos con su miembro, muy de prisa apretando mi mano más y más hasta que le vino un como ataque y aventó chorros blancos, que se quedaban colgados en los panalitos de los adobes" (14). El erotismo prohibido y transgresor en Nandino, conecta los deseos de dos seres "discontinuos", que al fundirse en el deseo forman una unidad "continua", según los términos de Georges Bataille. El erotismo como algo sagrado, según la concepción del autor francés, está mediado por el sacrificio que arroja una víctima sacrificada. En el universo de lo heterosexual, la parte femenina se convierte en la víctima, mientras que la masculina aparece como el sacrificador. En el caso de Nandino, el papel de la víctima es modificable; en ocasiones es él, mientras que en otras es su amante en turno.

En el capítulo titulado "Laura, la pelona", se advierte un "amor platónico" por una niña muy masculina que inquieta a Nandino a la edad aproximada de doce años, pero al separarse, se termina ese efímero amor infantil. Con Laura no hay un sacrificio, puesto que no existen contactos eróticos significativos, pero sí cuando establece prácticas zoofílicas con "la mariposa", una chiva propiedad de su padre. Lo mismo sucede con una gallina. El asesinato de Lencho, sus experiencias homosexuales placenteras, pero a la vez temidas y culposas, hacen que el Nandino niño se refugie en la realización de prácticas erótico-sexuales con animales hembras.

La etapa infantil es decisiva para la construcción de una identidad que aligere su fuerte carga de culpa, su angustia y soledad. La provincia, como espacio que condena las prácticas homoeróticas y, por el contrario, ofrece / impone la heterosexualidad normativa, se convierte en un espacio asfixiante. El erotismo en Nandino aparece a lo largo de su vida como 
una experiencia vinculada a la contemplación, a la unión del cuerpo y del alma de los amantes, y a una experiencia espiritual y corporal.

Deseo subrayar, por otra parte, que al hablar de los abusos de sacerdotes, Nandino, de manera velada, está a su vez denunciando las perversiones de los curas, a pesar de tener firmes sus creencias religiosas. Al presentarlos como seres humanos que reprimen sus deseos, se observa que el poeta rompe con la concepción ortodoxa del recato y la casi santidad que profesan los curas: "Todos se regaban por los salones y se cambiaban los cuerpos desvestidos. Era Sodoma Nueva” (47). La iglesia como institución esconde sus propias perversiones y pecados, aunque las condene y sancione con un discurso que al interior se transgrede.

La iglesia, la familia y la sociedad coculense asfixian al Nandino adolescente, quien establece contactos homoeróticos desde la clandestinidad. Su llegada a la ciudad de México — donde hace estudios de medicina-, le permite ciertas libertades, pues de acuerdo con lo que Georges Bataille dice sobre la transgresión: "La prohibición y la transgresión responden a esos dos movimientos contradictorios: la prohibición rechaza la transgresión, y la fascinación la introduce" (72). Reconociendo plenamente su homosexualidad, Nandino actúa con mayor libertad en la capital. Al conocer a gente como Xavier Villaurrutia y Salvador Novo principalmente, establece otra forma de vida, se relaciona sexualmente con hombres jóvenes (efebos); sin embargo, la búsqueda incesante del amor es una constante en todas las etapas de su vida.

A las relaciones de Nandino, así como a la búsqueda del amor que se funde con el cuerpo, se le puede aplicar el término de "erotismo de los corazones" de Bataille, pues existe en Nandino un complemento entre la experiencia erótico-sexual y la búsqueda de un amor donde se involucre el corazón con el acto carnal gozoso: "el acto sexual con amor se siente realmente puro" (170).

El acto sexual en el poeta cumple con ciertas características rituales que se repiten más o menos con los muchos amantes que dice haber tenido en su vida. Las descripciones eróticas que hace el poeta, hablan de un erotismo desvinculado de la idea de la reproducción como un fin práctico. Al rechazar la idea de la procreación, Nandino piensa en el goce personal y en el de su amante fundido en un solo gozo: "continuidad".

Amores homoeróticos significativos en la juventud son los contenidos en los capítulos "Adonis", "Orfeo", "Salón México", "Apolo" y "Hermes". El poeta — a diferencia de Salvador Novo- no menciona el nom- 
bre de pila de sus amantes y opta por ponerles otro para conservar su anonimato. Las características de estos jóvenes son similares: violentos, de pretensiones heterosexuales, machos —a la vez que pasivos en las relaciones sexuales - y dispuestos a ocupar un lugar simbólico como hijos o como acompañantes de un Nandino terriblemente hambriento de ternura y deseo carnal. Sobre las pretensiones heterosexuales y los galanteos de Adonis con muchachas de su edad, Nandino escribe: "Su reacción me lastimaba; veía el ridículo final de mi soñado romance" (91). Del joven Apolo dice: "Él era hombre y yo maliciaba que, de manera disimulada, se le iban los ojos con las mujeres y, en silencio, me moría de celos" (161). De Hermes, menciona: "Hermes era machito; le gustaban las mujeres. Había crecido y las muchachas le echaban los ojos. Un día me dijo: “¿Me dejas tener una novia para disimular? Te prometo que no te engaño y que no te dejo de querer. Nomás para pasar el tiempo" (174).

A partir de las experiencias de Nandino con efebos entregados solamente al "erotismo de los cuerpos", se observa una carencia afectiva y una búsqueda constante del "erotismo de los corazones"; de la fusión del cuerpo y el alma: "esa interminable ansiedad de buscar el amor. Yo no podía vivir sino enamorado o buscando el amor. Esa era mi vida, de tal manera que mi preocupación principal fue saciar esas dos necesidades implacables y obsedentes" (189).

Lo que para un crítico como Víctor Roura es una exhibición de la impulsiva conducta homosexual de Nandino, para mí es un testimonio de un intelectual en búsqueda constante del amor. Desde la subjetividad del poeta, y con las omisiones o exageraciones que pueda hacer de sus vivencias, Juntando mis pasos no es en ningún sentido un texto exhibicionista. La búsqueda constante del amor homosexual y el sentimiento de carencia del amor y la constante soledad, son temas importantes a lo largo del texto y de sus poemas, que nos permiten conocer la vida del creador. Sobre la vida homosexual, Nandino escribe: "Buscar, siempre buscar es el destino del homosexual. Su amor es un amor sin compromiso" (40). Más adelante, dice: "Nadie sabe la vida tan tremenda que tiene que afrontar un homosexual" (54). Sin embargo, la búsqueda donde se funden el cuerpo y el alma es constante: "Mi placer mayor era buscar el amor, y el amor se consigue solamente experimentando cuerpos ajenos, hasta encontrar la afinidad precisa del espíritu y la carne" (57).

El tema de la infidelidad asociado a la culpa es también muy constante en Juntando mis pasos. Experimentar placer con otros cuerpos le produce 
al poeta una culpa, a la vez que le reafirma la entrega erótica del cuerpo y el alma de su amante en turno. Así, sufrimiento, posesión, búsqueda, muerte y pasión, conviven en los actos eróticos que Nandino establece.

Dice Georges Bataille que:

Las posibilidades de sufrir son tanto mayores cuanto que sólo el sufrimiento revela la entera significación del ser amado. La posesión del ser amado no significa muerte, antes al contrario; pero la muerte se encuentra en la búsqueda de esa posesión [...] le parece al amante que sólo el ser amado — cosa que proviene de correspondencias difíciles de definir, donde a la posibilidad de unión sensual hay que añadir la de unión de los corazones - puede, en este mundo, realizar lo que nuestros límites prohíben: la plena confusión de dos seres, la posibilidades de dos seres discontinuos [...] La pasión nos adentra en el sufrimiento, puesto que es en el fondo, la búsqueda de un imposible (25).

Como una forma del ser discontinuo, Bataille afirma que el erotismo de los cuerpos tiene un halo de siniestro, y que el erotismo de los corazones a menudo se da cuando hay una afección recíproca de los amantes. En el caso de Nandino, sus experiencias homoeróticas están con frecuencia desprovistas de esa reciprocidad afectiva por parte de sus amantes. La entrega en Nandino parece ser algo que sólo existe de su parte y, como él está en desventaja al tener una entrega erótica con el cuerpo y el alma, experimenta culpa, siente cierta traición al ser "infiel":

Mi placer mayor era buscar el amor, y el amor se consigue solamente experimentando cuerpos ajenos, hasta encontrar la afinidad precisa del espíritu y la carne [...] Muchas veces de una infidelidad corría a meterme al lecho donde estaba mi amante, y lloraba en silencio por haberlo engañado y reconocía que mi amor por él era firme y absoluto (57).

Ser infiel, para afianzar el amor y entrega hacia el otro, es algo que sufre y goza. En el capítulo "Orfeo" vuelve sobre la idea de la traición y la culpa. Llama la atención la casi trascripción que hace de la cita anterior; pareciera que se trata de frases hechas a base de estarse recriminando sus actos:

Pensaba que engañar a mis amantes era probar mi propio amor y, después del engaño, regresaba a mi lecho, me acurrucaba entre sus brazos, 
me arrepentía secretamente y confirmaba que lo adoraba con toda mi alma (107).

En el capítulo "Conclusiones" nuevamente justifica sus infidelidades para probar su amor verdadero: "[...] siempre jugué limpio, aunque nunca fui fiel a mis amantes, porque mi temperamento admitía la infidelidad para probarme a mí mismo que mi amante era insustituible” (158). La infidelidad deviene en culpa porque sabe que se trata de una transgresión y una traición, aunque también es una forma de destruir lo construido, de deformar lo que llama "mi poema humano".

Al vivir en un vaivén constante de prohibiciones y desafíos, Elías Nandino establece con sus amantes la dinámica del padre protector y el amante. Este incesto simbólico lo coloca en el rol del hombre activo y protector que siente fascinación por esa relación amante / hijo:

Yo aseguro que la terminación con cada amante me costó meses de dolor y de orfandad, porque los amé no solamente como amantes, sino como hijos y, más, con la horrible y maravillosa sensación de que cometía un incesto" (159).

Como una táctica de seducción, las relaciones con efebos, que Nandino refiere, se dan siempre por la ocupación de roles inmodificables: los jóvenes son pasivos, pero al cuidado y protección de un simbólico padre incestuoso que les provee sus necesidades económicas y que ayuda a varios de ellos en sus estudios. A Hermes le compra todos los materiales que necesita para estudiar pintura; mientras que a Ulises le da dinero y estudios. ${ }^{7}$

De todos los amantes que Nandino dice tener, es este último el único que logra llegar al erotismo de los corazones. Cuando Nandino le es infiel, el efebo traicionado reacciona:

¡Cabrón, debes saber que yo vine contigo porque tenía necesidad de hacer carrera! ¡Accedí a todo lo que quisiste porque yo quiero recibirme! ¡Yo nunca pensé que te entregaría mi alma, estaba bien que gozaras de mi cuerpo, pero ahora vengo a decirte que si te vuelvo a encontrar con

\footnotetext{
${ }^{7}$ En Elías Nandino: una vida no/velada, el autor refiere cuatro relaciones homosexuales que en la autobiografía de Nandino no aparecen. Uno de ellos es Polín, un joven al que también se entrega — con el cuerpo y el corazón—y al que trata como amante/hijo:
} 
un cabrón, lo saco a patadas [...] Tú has sido mi amigo, mi amor y mi padre (186-187).

En Juntando mis pasos se advierte una concepción cambiante sobre la homosexualidad en la etapa infantil, en la juventud y en la madurez. En la niñez, la homosexualidad es placer, culpa y necesidad por conocer, mientras que en la juventud es placer, deseo de aventura y búsqueda constante del amor-pasión. En la etapa de la madurez, se lee cierta soledad, impulsos reprimidos por poseer lo que ya no es posible debido a la impotencia sexual del poeta, a su estado de salud precario y a los problemas auditivos y visuales. De manera significativa, para hablar de la añoranza del pasado, Nandino escribe pasajes con ciertos tonos líricos. Para referirse al año 1972, cuando tiene que reducir su práctica médica a consecuencia de su mal estado de salud, dice: "Había perdido los ojos en las yemas de los dedos para ver en las entrañas de los cuerpos, adivinar con el tacto el tamaño de los tumores" (191). Sobre su impotencia sexual, añade: "mi orgasmo en frío, como gotas de llanto en medio de una tormenta. Y hubo noches de hasta cuatro tormentas. Era un celeste infierno" (197).

Al decidir apartarse de las prácticas sexuales por su impotencia, Nandino cuenta en el capítulo "Erotismo al rojo blanco" su rechazo hacia un niño de doce años que entra a su cuarto de baño con el objetivo de involucrarse sexualmente con el poeta:

Sin decir palabra, puso todo en el clavijero — su pequeño pene estaba completamente erecto- $-y$, de manera directa agarró mi sexo para succionarlo. Yo lo aparté hasta con un poco de coraje, y le dije: "Eso no se hace". Al ver mi actitud el chico se avergonzó (195).

Apartado ya de su carrera de médico y estando enfermo, escribe el poemario Erotismo al rojo blanco (1983), libro con temática eróticohumorística, dividida en nueve secciones. Considero a Erotismo al rojo blanco como un "falo literario" que sustituye la imposibilidad tangible de la consumación y el gozo sexual del poeta. El autor hace uso de la memoria para revivir un pasado mejor donde la salud y la libertad

"Le compré ropa y lo aboné en la casa como mi compañero de cuarto con el pretexto de que era mi sobrino" (80). 
ejercida lo llevan al gozo; mientras que en el presente de la vejez, sólo le queda reír de su impotencia y escribir en papel su cuerpo y el de sus amantes. En la presentación de este libro, Nandino declaró: "Los poetas tenemos una cosa: en un poema podemos realizar el deseo de un cuerpo. La creación poética te trae a la ficción [la posibilidad] de tener un cuerpo entre tus manos" (1983, grabación).

Erotismo al rojo blanco se corresponde con Juntando mis pasos en el sentido de que ambos textos forman una unidad, son la revelación de un escritor homosexual que vierte sus deseos desde la escritura, que recoge a través de la memoria —incluyendo la memoria corporal y no sólo la intelectiva-, fragmentos de su sexualidad gozosa y sufrida a lo largo de su vida.

Carlos Monsiváis en el prólogo a Erotismo al rojo blanco habla de una erotomanía y una grafomanía de los poemas incluidos en este texto. Nandino recuerda, siente y lo vierte en su escritura. Aunque muchos de estos poemas — como en el caso de los "Alburemas"— 8 son eróticohumorísticos, hay una mezcla de tragedia y juego con su propio sexo cansado y con el dolor por no poder seguir realizando lo que llama "un poema humano".

En Juntando mis pasos, Elías Nandino habla sin tapujos de su vida literaria y sexual. El texto se puede juzgar bajo criterios estéticos y no morales. El texto de Nandino habla detalladamente de las dos grandes pasiones en su vida: la poesía y el acto amoroso-sexual pues, de acuerdo con Bataille: "La poesía lleva al mismo punto que todas las formas del erotismo: a la indistinción, a la confusión de objetos distintos. Nos conduce hacia la eternidad, nos conduce hacia la muerte y, por medio de la muerte, a la continuidad: la poesía es la eternidad" (30). Efectivamente, Elías Nandino deja de ser un ser "discontinuo" cuando logra la fusión con la poesía. La creación poética sustituye al acto sexual; es una forma de morir, gozar, recuperar fragmentos de la memoria para, de esta manera, no morir del todo, sino continuarse a través de la poesía.

\footnotetext{
${ }^{8}$ Sobre esta sección del libro, escrita en 1962, Elías Nandino declaró durante la presentación de su libro en abril de 1983 en la sala Manuel M. Ponce del Palacio de Bellas Artes: "Estos poemas yo los hice buscando con ingenio, los dobleces de las palabras. En el fondo es una especie de choteo a mí mismo porque llega un día en que uno realmente aborrece su carne enjuta y extraña su juventud y entonces se vale burlarse de uno mismo y, de cierto modo, tener cierto consuelo (1983, grabación).
} 


\section{BiBLIOGRAFÍA}

Aguilar, Enrique. [1986]. Elías Nandino: una vida nolvelada. México: Océano, 2000 (El día siguiente).

Bataille, Georges. [1976]. El erotismo. Barcelona: Tusquets, 2005 (Ensayo).

Espinosa, Jorge Luis. "Reeditan polémica biografía sobre el poeta Elías Nandino" en Unomásuno, México, 1 de diciembre de 2002: 31.

Monsiváis, Carlos "Los gays en México: la fundación, la ampliación, la consolidación del ghetto" en Debate feminista, 26. México (octubre 2001): 89-115.

- "La emergencia de la Diversidad: las comunidades marginales y sus batallas por la visibilidad" en Debate feminista, 29. México (abril 2004): 187-205.

Roura, Víctor. "Los pasos de Nandino" en El Financiero, México, 13 de junio de 2000: 70.

Rosado, Juan Antonio Erotismo y misticismo. La literatura erótico-teológica de Juan García Ponce y otros autores en un contexto universal. México: Praxis / Universidad Autónoma de la Ciudad de México, 2005.

Nandino, Elías [1983]. Erotismo al rojo blanco. México: Ágata, 1991.

-. Juntando mis pasos. México: Aldus, 2000.

- Erotismo al rojo blanco [presentación del libro y lectura de poemas en la sala Manuel M. Ponce del Palacio de Bellas Artes]. México: Consejo Nacional para la Cultura y las Artes, Instituto Nacional de Bellas Artes (7 de abril de 1983) [grabación].

FECHA DE RECEPCIÓN: 20 de septiembre de 2007.

FECHA DE ACEPTACIÓN: 30 de mayo de 2008. 